\title{
Assessing the physical planning and management of waste in the O.R. Tambo District Municipality: implications for management
}

\author{
S. Buso ${ }^{1}$, M. D. V. Nakin ${ }^{2} \&$ A. Abraham ${ }^{1}$ \\ ${ }^{I}$ Department of Environmental Science, Walter Sisulu University, \\ South Africa \\ ${ }^{2}$ Risk and Vulnerability Assessment Centre, Walter Sisulu University, \\ South Africa
}

\begin{abstract}
Solid waste management has become one of the key problems in the world and has ranked in the top five of the most challenging problems for city managers. However, it receives little attention compared to other urban or municipal management issues. The aim of this study was to identify the manner in which solid waste was managed and the response planning to waste generation and disposal with challenges that were faced by five local municipalities in the O.R. Tambo District Municipality. This was archived by mapping waste management activities such as street bin distribution, illegal dumping and municipal landfill sites through the recording of coordinates and picture taking using GPS and digital cameras, respectively. Map analyses and production was done using ARCGIS 10.1 software. Pearson's Product Moment Correlation Coefficient was used to determine the relationship between bin distribution and illegal dumping. The calculated results showed no correlation between bin distribution and illegal dumping. There were also differences on waste conditions, bin distribution and illegal dumping in towns of the five local municipalities. A total of nine landfill sites were found with four licensed and five illegal. The results suggest not only the placement of bins close to waste generation points, but also the use of different sizes of bins depending on waste generation volumes. The establishment of waste minimisation programs, environmental education, awareness campaigns, workshops and law enforcement
\end{abstract}


was suggested in each local municipality as this may reduce solid waste workloads and the disposal of solid waste management in municipalities.

Keywords: waste generation, minimisation, measures, management, disposal, illegal dumping, environment, awareness, municipalities, bin distribution.

\section{Introduction}

Managing solid waste has been reported to be one of the biggest challenges in urban areas of all sizes in the world, from mega-cities to the small towns and large villages, which are home to the majority of humankind [1]. Solid waste represents a major problem to the government of developing nations, and amongst others it is the biggest challenging issue for sustainable development in municipalities [2]. There are many factors contributing to the physical conditions of waste management and planning, these range from activities like waste generation, minimisation and avoidance, source separation, storage, handling, transportation, recovery and recycling, treatment and disposal [3]. Other factors include distribution of bins, size of the receptacles compared to waste generation capacity, population growth and population density, educational level or environmental awareness, data management or waste information system, law enforcement, collection methods or models, road networks and infrastructures, collection time frames, collection vehicles, visibility of workers (waste pickers, street sweepers and collectors), solid waste visibility, cleanliness, greening initiatives, sewage spillages, illegal dumping and waste disposal facilities (landfill sites) [4]. All these parameters are the determining factor of how the system of waste management should be coordinated and conducted [5].

Unmanaged solid waste results in a bad odour created around the area, which makes the environment Unpleasant. This also affects the economic factor, market value of the area decreases if there is a badly maintained waste area nearby as it poses a bad aesthetic [6]. The way in which waste is produced and discarded gives a key insight into how people live [7]. Cleanliness of the city is a good reflector of good knowledge and behaviour in terms of awareness and governance of the city [8]. If a city is dirty, the local administration may be considered ineffective or its residents may be accused of littering and illegal dumping [9]. The quality of waste management services is a good indicator of a city's governance [1].

Despite the fact that there are rules and regulations that are governing waste management in South Africa, like the National Environmental Management: Waste Act (No 59 of 2008) which asserts roles of both national and provincial government in waste management. Local Municipalities in this regard are assigned with a responsibility of planning, implementing and enforcement of appropriate waste minimization and recycling initiatives through planning and capacity building, as well as to promote a safe disposal for a healthy environment. Good municipal solid waste management practices requires collection of critical information which is not just for keeping the records up to date but used effectively for taking corrective measures as well as proper planning for the future" [10]. The aim of the study was intended to identify the 
manner at which waste is managed and response planning to waste generation challenges faced by five local municipalities in the O.R. Tambo District Municipality. To achieve this, physical conditions of the municipalities on waste management were investigated. This study was intended to sensitize municipalities to their role in promoting sustainable development through proper planning, management, minimization and disposal of solid waste.

\section{Materials and methods}

Field observations were conducted in the O.R. Tambo District Municipality (Figure 1) local municipalities of Port St John's, Nyandeni, Mhlontlo, King Sabatha Dalindyebo and Ingquza Hill to determine bin (waste receptacle) distribution in relation to sources of waste generation and illegal dumping, and infrastructure which includes landfill sites in the towns of the five local municipalities. Coordinates of street bins, illegal dumping and landfill sites for each local municipality were recorded using GPS. ARC GIS 10.1 was used to produce maps. A digital camera was used to take pictures reflecting waste conditions on the ground. The same procedure was undertaken in each local municipality.

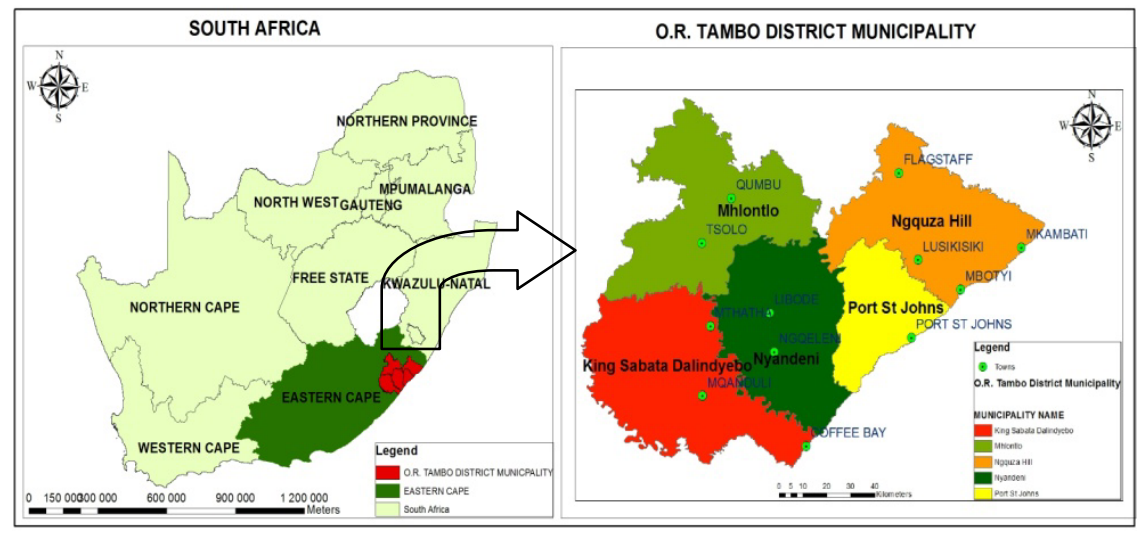

Figure 1: $\quad$ Map showing the study area.

\section{Results}

\subsection{Bin distribution, illegal dumping and waste conditions}

Results revealed differences in bin distribution among towns in each local municipality. The distribution of bins in Flagstaff was found on the main road of the town and also in places where there were few businesses (Figure 2, left). Illegal dumpings were visible in the back streets of the town next to the informal 
business areas. Some waste was also found dumped next to the main road close to businesses (Figure 2, right). Some of illegal dumpings were found in streams, drainage system and also where sewage flowed out of the system.

There were no street bins in Lusikisiki (Figure 3, left). Illegal dumpings were highly visible (Figure 3, right). Waste in Lusikisiki was also dumped in environmental sensitive areas such as wetlands.

In Port St John's Street bins were evenly distributed and no illegal dumping was found (Figure 4, left).

Bin distribution in the streets of Ngqeleni were evenly distributed (Figure 5, left). Illegal dumping and littering were also found with bins (Figure 5, right).

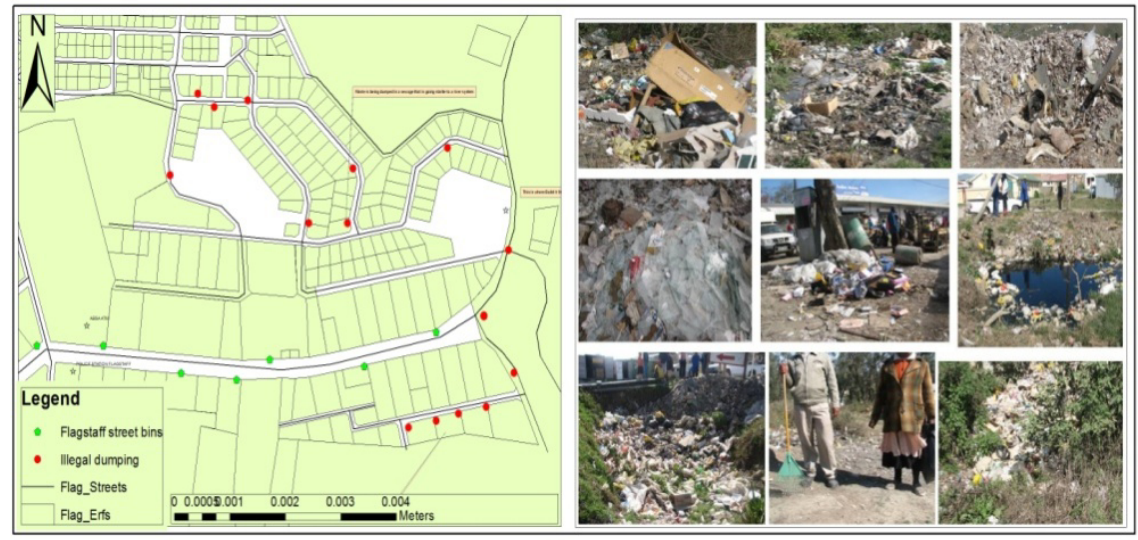

Figure 2: $\quad$ Bin distribution, illegal dumping (left) and waste conditions (right) at Flagstaff in Ingquza Hill Local Municipality.

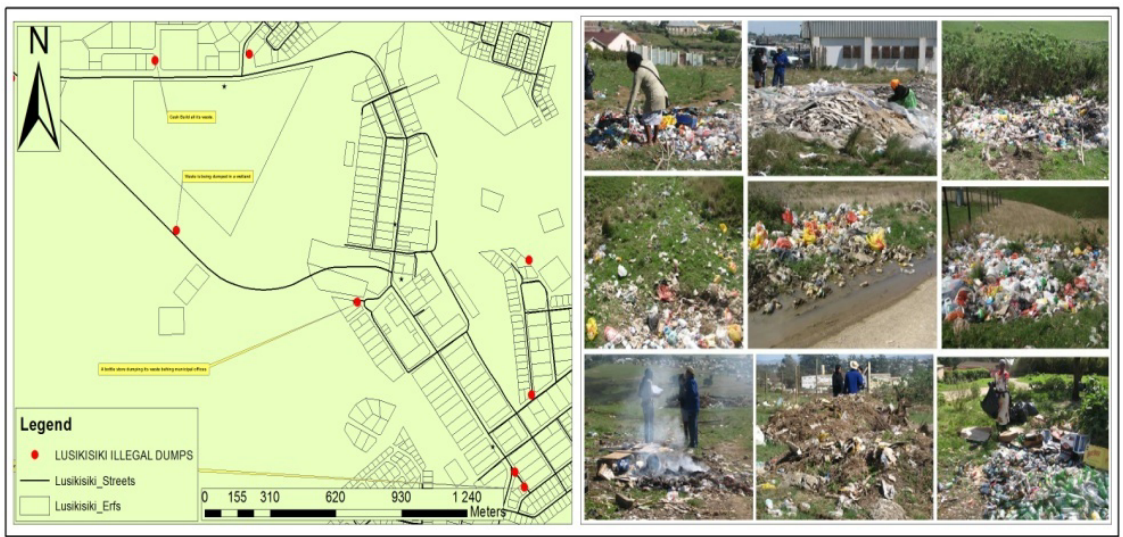

Figure 3: $\quad$ Illegal dumping (left) and waste conditions (right) at Lusikisiki in Ingquza Hill Local Municipality. 


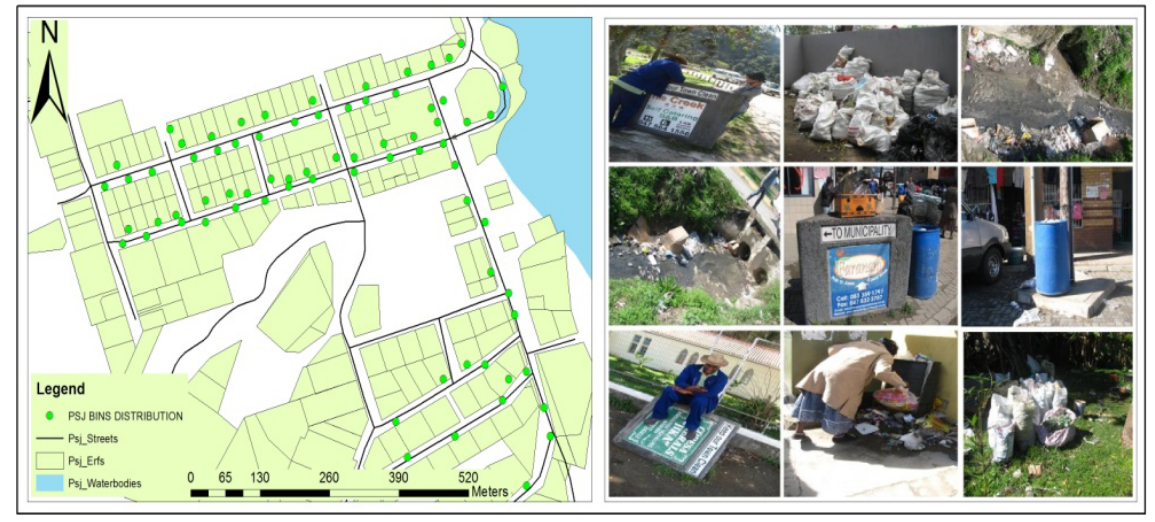

Figure 4: $\quad$ Bin distribution (left) and waste conditions (right) in Port St John's Local Municipality.

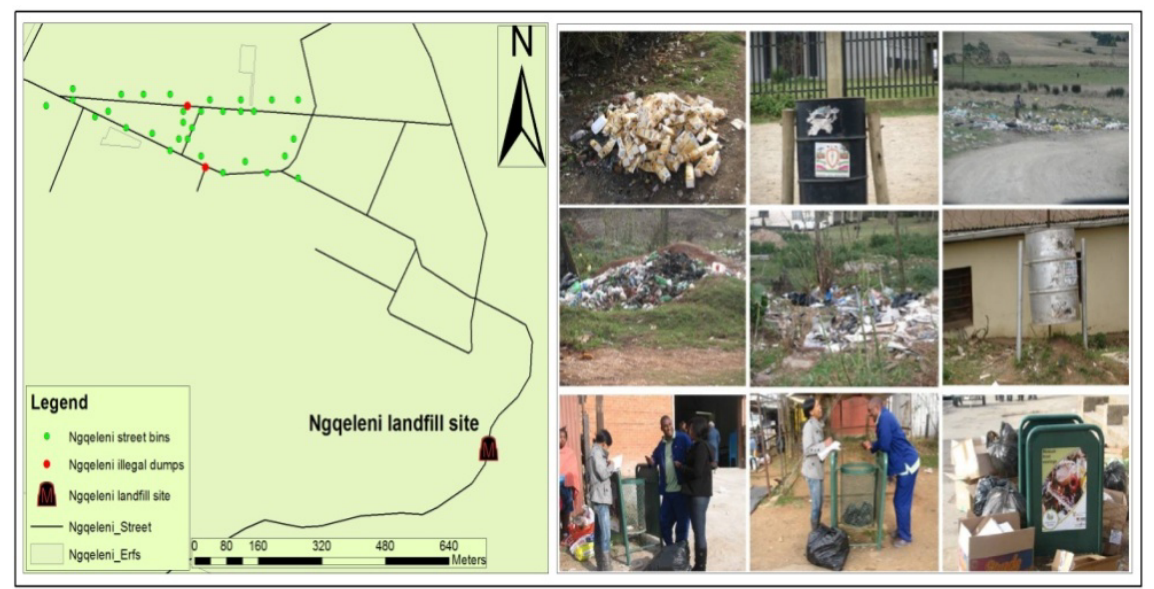

Figure 5: $\quad$ Bin distribution, illegal dumping (left) and waste conditions (right) at Ngqeleni in Nyandeni Local Municipality.

In Mhlontlo Local Municipality street bins were evenly distributed (Figure 6, left). There was an open space within town next to the informal trading, where people were dumping. Waste was scattered next to the bin and was overflowing. There was also the use of skippers in Mhlontlo (Figure 6, right).

In Mthatha street bins were distributed throughout the town (Figure 7, left). Bins were small and waste was overflowing from the bins. Street bins in Mthatha were also vandalised (Figure 7 , right). Littering was also highly visible in Mthatha. 


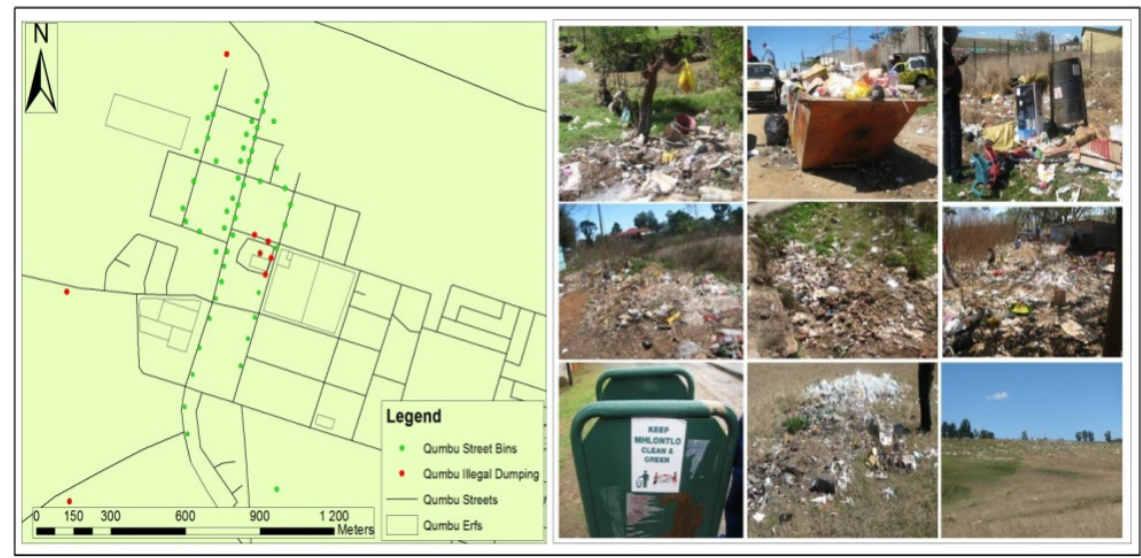

Figure 6: Bin distribution, illegal dumping (left) and waste conditions (right) at Qumbu in Mhlontlo Local Municipality.

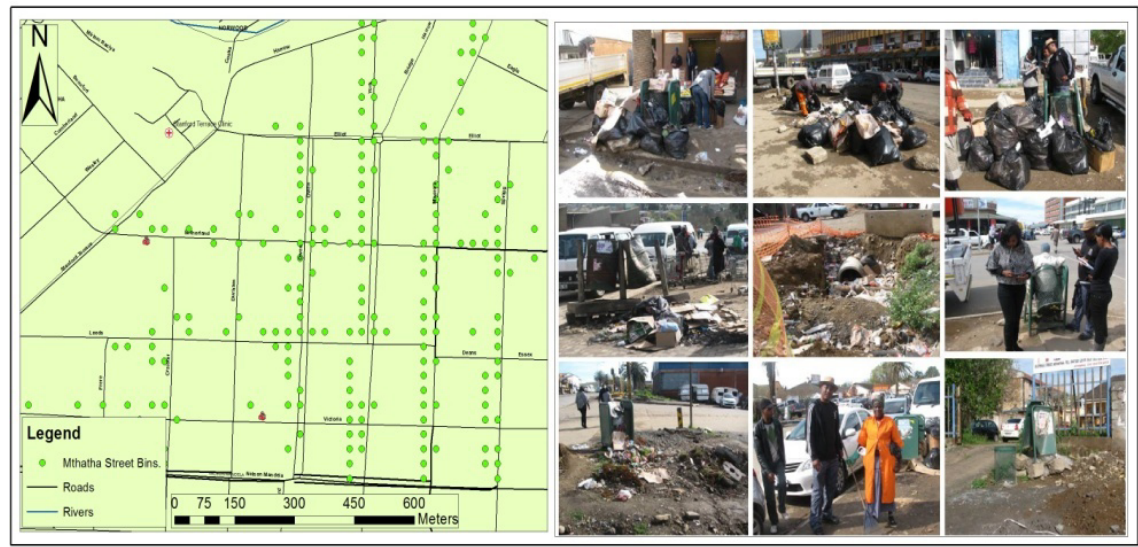

Figure 7: $\quad$ Bin distribution (left) and bin conditions (right) at Mthatha in King Sabatha Dalindyebo Local Municipality.

In Mthatha illegal dumpings were highly visible in open spaces, in rivers and in streets corners. Mentally disabled people were taking waste out of the bins in search of food, and waste was blocking the drainage system and resulting in sewage flowing on streets (Figure 8). 


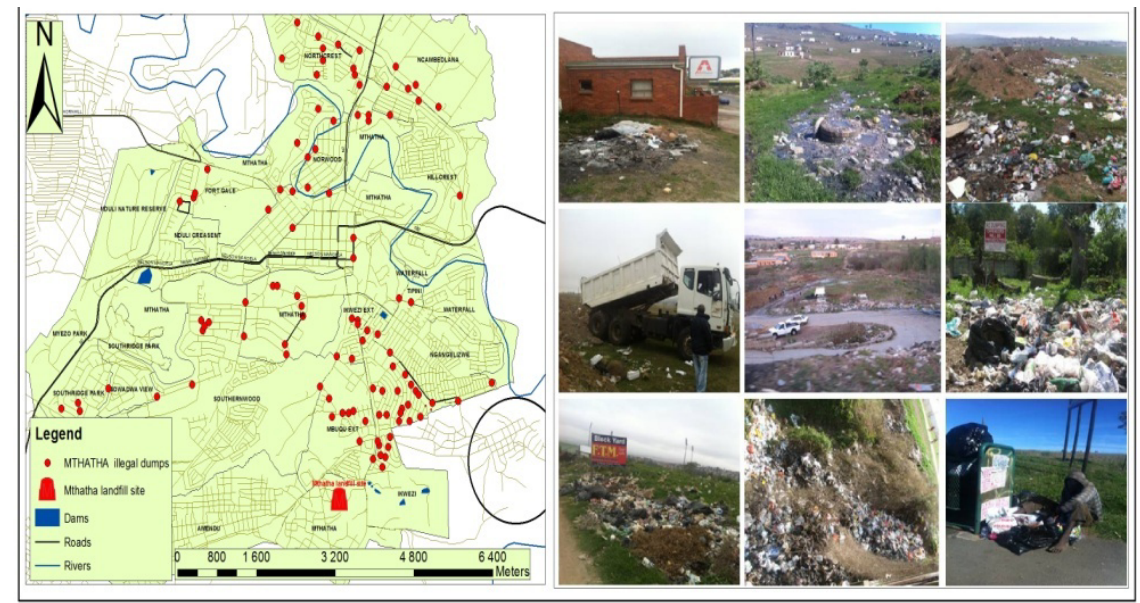

Figure 8: $\quad$ Illegal dumping (left) and its conditions (right) at Mthatha in King Sabatha Dalindyebo Local Municipality.

\subsection{Landfill sites}

All nine towns in O.R. Tambo District Municipality at each had landfill site, four of which were operating legally (shown in green colour), and five with no permits (shown in black and red colour). The landfill sites that had permits were found in Port St John's, Qumbu, Tsolo and Mqanduli, while in Mthatha, Flagstaff, Lusikisiki, Libode and Ngqeleni had no permits. Landfill sites in Qumbu, Tsolo, Mthatha, Port St John's and Mqanduli were fenced, while in Flagstaff, Lusikisiki, Libode and Ngqeleni were not fenced (Figure 9).

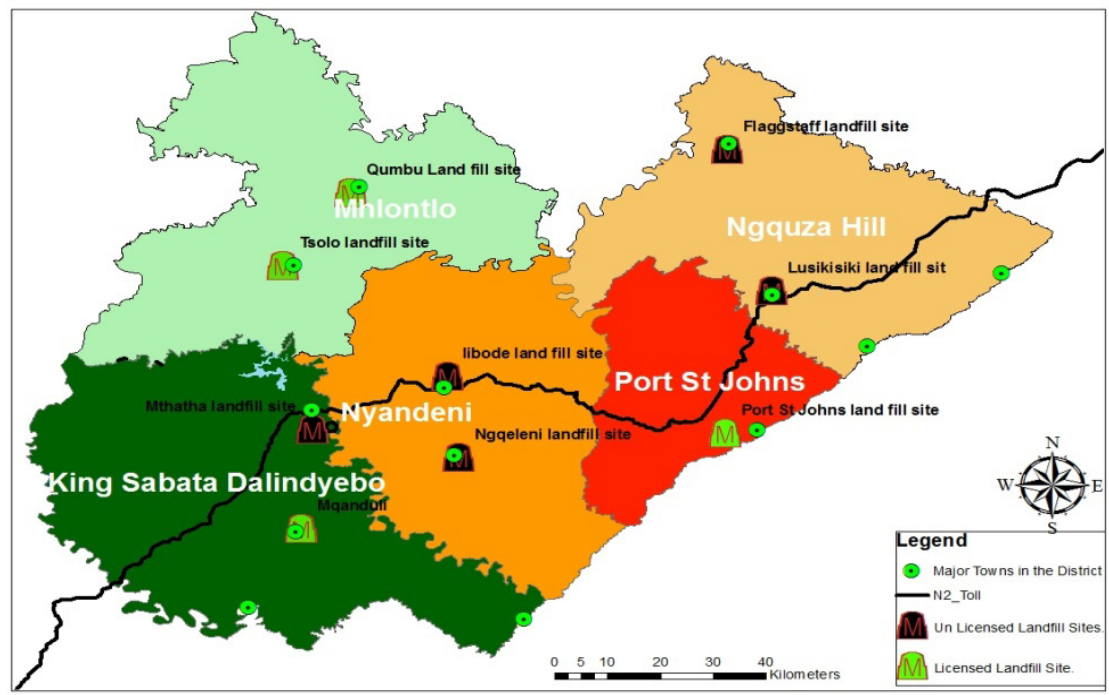

Figure 9: Landfill sites in local municipalities of O.R. Tambo District Municipality. 


\section{Discussion}

Results of this study revealed differences in towns in each local municipality on the distribution of bins, illegal dumping and waste conditions. Bin distribution differs not only in local municipalities, but also in towns within local municipalities. There was a positive correlation between bin distribution and illegal dumping. It was also noted that the sizes of bins used in municipalities were varying in sizes, and were not located according to the waste generation volumes of certain areas; some were small resulting in waste overflowing and littering. Except for Port St John's, landfill sites in local municipalities were not operating according to the national guidelines, even though some had permits.

Parameters like, distribution of bins, size of the bins compared with waste generation capacity, population growth and population density, educational level or environmental awareness, illegal dumping and land filling (disposal) were identified as key findings of the study. Data management or waste information systems, collection methods or models, road network, collection time frames and collection vehicles were also considered when assessing the physical conditions of municipalities in each town. As part of the logistics management and spatial planning for waste management, it was important to develop the adoptability of the system for better management around these parameters [5].

Bin distribution in Port St John's, Nyandeni, King Sabatha Dalindyebo and Mhlontlo local municipalities was distributed evenly throughout the towns, while in Ingquza Hill Local Municipality bins were not evenly distributed. In Lusikisiki there were no street bins at all. According to the officials from the municipality, street bins were all burnt during the strike, and they were made of plastic. However, there were waste pickers allocated to areas where there was dumping, although there were exceptional cases in places next to business areas where waste was dumped adjacent to the store.

Distribution of bins in flagstaff was on the main road of the town, this is where the town is located and its market activities took place. Some of the bins that were in the business area were vandalized and no longer operational due to the high population in town and the competition for space for trading. Ahmed [11] reported that improper management of solid wastes was not only due to the municipality not doing their work properly or to work negligence, but also due to the old conventional working methods which needed to be upgraded with the advanced system like GIS and a better management system. Municipal bodies were unable to prove a $100 \%$ efficient system and even were not able to reach the efficiency of $60 \%$ [12].

In terms of the size of the bins compared to waste generation capacity, the study found that in all municipalities bins that were used varied between 100 to 200 litre bins in size and also skippers that were used for collecting waste from business. Waste was found scattered around the bins and the skippers. This was due to the fact that waste generation capacity in certain areas of towns like Mthatha, Qumbu, Flagstaff, Mqanduli and Libode were more than the size of the bins, and collection intervals were not responding to the waste generation capacity. Waste bins that were used in all these local municipalities were 
uncovered and exposed to any type of waste removal from them. Unprotected waste is known to be the carrier of many kinds of diseases like cholera, diarrhoea, dysentery and tetanus [6].

The accumulation of waste around the bins was the common problem faced wherever there is an uncovered bin and there were no proper base platform for bins [11]. Another challenge in towns like Mthatha was the availability of mentally disturbed people who were always looking for something to eat, so they took out waste from bins. Street bins in Mthatha were also vandalised, some knocked down by cars. As a result there was an unpleasant environment and smell around the bin area. Virk et al. [6] noted that such situation also affects the economic factor and market value of the area decreases. The accumulated waste may create health problems becomes a breeding ground for insects, flies, different bacteria, and micro-organisms. The decaying matter from waste provides suitable material for harmful insects (mosquitoes and flies) to thrive and rapidly cause diseases [6].

Population growth and density were also found to be among the contributing factors in the situation and the condition of waste management in O.R. Tambo District Municipality. In towns like Mthatha, Lusikisiki, Flagstaff, Port St John's, Qumbu and Tsolo, it was noted that there was high population density during the day shopping purposes, and this contribute highly to the generation of waste and high loads of waste to manage. Moreover during the day, municipal officials found difficulty in cleaning the streets because of overcrowding by people in town.

The growing trend of urbanisation of the population where there is ruralurban movement also tends to increase the per capita generation of waste. Population tends to have higher incomes, higher consumption of goods and, consequently, higher generation of waste compared to rural populations [13]. Undeniably, the rapid rate of urban growth is causing social and economic strains, some of which manifest themselves in environmental problems. The magnitude of the problem is, however, only partially reflected in the higher amount of solid waste generated each year [7]. Although the high rate of urbanization in African countries implies a rapid accumulation of refuse, social and economic changes that most countries have witnessed since the 1960s have also contributed to increases in waste generated per capita [14]. Consequently, common features of African urban areas are stinking heaps of uncollected waste, waste disposed of haphazardly by roadsides, in open spaces, or in valleys and drains, and waste water overflowing onto public lands [7].

This study found that local municipalities in O.R. Tambo District Municipality had little or no programs for environmental education and consequently, signs of "no dumping" were ignored. The other challenge in these local municipalities was the limited number of professional staff in the strategic positions of the field and some were unqualified. Environmentally sound waste management must go beyond the mere safe disposal. It should include minimization actions, reuse and recycling activities, proper treatment and finally safe disposal. But its success is highly dependent on an informed and participatory public. Public participation is considered to be an important part of 
waste management strategies [15]. Public awareness and understanding the importance of waste management and its benefits are consequences of education and awareness raising campaigns. These campaigns are also responsible for more involvement and participation of the public.

UNESCO [16] pointed out that education is a powerful tool that should be used towards building a more sustainable society. Through education it is possible to build a society that is better informed, with critical views and wiser and more responsible people. Mariwah [7] noted that coordination for waste management should be encouraged within the context of environmental education, training and awareness and stricter enforcement of waste by-laws. Education and public participation raise awareness among the community about the importance of a clean environment. The level of commitment to the ongoing waste management strategies in a certain area will certainly be increased if people are involved and their views and needs respected and addressed [15].

Except for Port St John's local municipality, illegal dumpings in Ingquza hill, Mhlontlo and King Sabatha Dalindyebo local municipalities were found in many areas relative to Nyandeni local municipality. Kalule [17] noted that illegal dumping was due to the fact that waste management has traditionally not been seen as a priority issue in municipalities and hence it has not enjoyed much support from most structures and planning of the municipalities. Port St John's was found to an exceptional case, because waste management was highly coordinated and prioritized. Port St John's is regarded as tourism destination in the region.

Waste disposal (land filling) in O.R. Tambo District Municipality was found not practiced in an environmental sustainable manner. Out of nine landfill sites, there was only one in Port St John's, which was operating according to the landfill guidelines, even though there were 4 that had permits. Williams [18] noted that at the beginning waste was required to be collected and transported by scavengers to an open dump one mile outside the city.

\section{Conclusion and recommendations}

Data management or waste information system, collection methods or model, road network, collection time frames, collection vehicles were found to be the most important elements that were contributing to the conditions of waste management in O.R. Tambo District Municipality. It is recorded that not only placement of bins close to waste generation points, but also use of different sizes of bins depending on waste generation volumes, the establishment of waste minimisation programs, environmental education, awareness campaigns, workshops and law enforcement were suggested in each local municipality as this may reduce solid waste workloads and disposal of solid waste management in municipalities.

\section{Acknowledgement}

We are grateful to the Department of Science and Technology (DST) and National Research Foundation (NRF) for funding this study. Walter Sisulu University is also thanked for logistic support. 


\section{References}

[1] United Nations Human Settlements Program (UN-HABITAT). Solid Waste Management in the World's Cities. London, Earthscan, Washington DC. 2010.

[2] Wiley, J. Sustainable Development in Practice, Case Studies for Engineers and Scientists. University of Surrey, London. 2004.

[3] Gondo, T. Spatial Planning and Open Space Integration in Urban Ethiopia: A Sustainable Accessibility Exegesis. REAL CORP 2012, Tagungsband Schwechat. http://www.corp.at. 2012.

[4] Xudong, C. Spatial Analysis and Evaluation System for the Planning of Regional Recycling Network: Empirical and Modelling Analyses in Japan. Nagoya University. Japan. 2012.

[5] Rahardyan, B., Matsuto, T., Kakuta, Y. \& Tanaka, N. Resident's concerns and attitudes towards Solid Waste Management Facilities. Hokkaido University. Japan. 2004.

[6] Virk, M. K., Singal, V. \& Sandhu, P. Awareness Among Urban Inhabitants About Waste Management and Its Impact on Environment. In:J. Hum. Ecol. 2004.

[7] Mariwah, S. Journal of Sustainable Development in Africa (Volume 14, No. 6, 2012). Clarion University of Pennsylvania, Clarion, Pennsylvania. 2012.

[8] Fiehn, H. \& Ball, J. Background research paper: Waste. South Africa Environment Outlook. National State of the Environment Project. Department of Environmental Affairs and Tourism: Pretoria, South Africa. 2005.

[9] Chen, X., Geng, Y. \& Fujita, T. An Overview of Municipal Solid Waste Management in China. Waste Management. 2010.

[10] Ramachandra, T. V. \& Sair, V. K. Exploring possibilities of achieving Sustainability in Solid Waste Management. In: Indian Journal Environmental Health, October. 2003.

[11] Ahmed, S. M. Using GIS in Solid Waste Management Planning, A case study for Aurangabad, India ISRN: LIU-IDA-D20-06/004 — SE. 2006.

[12] Ogra, A. Logistic Management and Spatial Planning for Solid Waste Management Systems using Geographical Information System. In: Map Asia, India. 2003.

[13] OECD. Addressing the Economics of Waste. Organization of Economic Cooperation and Development. 2004.

[14] Onibokun, A. G. \& Kumuyi, A. J. Governance and waste management in Africa. Canada, International Development Research Centre (IDRC). www.idrc.ca/publication/online books on 20/11/06). 2004.

[15] Kohlscheen, C. W. Towards Integrated Solid Waste Management in LowIncome Housing Areas In Durban, South Africa. Kungl Tekniska Hogskolan. Stockholm. 2003.

[16] UNESCO. "Education for Sustainable Development". 2001 http://www.unesco.org/education/esd/english/education/role.shtml 
136 Waste Management and The Environment VII

[17] Kalule, S. K. Integrated Waste Management Plan, O.R. Tambo District Municipality. Usk Consulting Environmental \& Waste. Eastern Cape South Africa. 2009.

[18] Williams, P. T. Waste Treatment and Disposal, second edition, the university of Leeds, UK. 2005. 